\title{
Korelasi antara Panjang Garis Sternoakromion dan Titik Penyuntikan Blokade Pleksus Brakialis pada Anestesi Vertical Infraclavicular Block Menggunakan Pencitraan Ultrasonografi pada Pria Dewasa
}

\author{
Dedi Fitri Yadi, Ike Sri Redjeki, Tatang Bisri \\ Departemen Anestesiologi dan Terapi Intensif \\ Fakultas Kedokteran Universitas Padjadjaran/Rumah Sakit Dr. Hasan Sadikin Bandung
}

\begin{abstract}
Abstrak
Anestesi regional untuk operasi di daerah lengan bawah dapat dilakukan blokade pleksus brakialis vertikal infraklavikula. Penelitian ini bertujuan menemukan korelasi antara panjang garis sternoakromion dan letak penyuntikan menggunakan pencitraan ultrasonografi untuk vertical infraclavicular block (VIB) pada pria dewasa. Penelitian potong lintang dengan mengukur titik tengah garis antara fosa jugularis dan akromion pada 48 pria dewasa. Pencitraan ultrasonografi dilakukan menggunakan probe linear untuk menentukan letak penyuntikan. Penelitian dilakukan di Rumah Sakit Dr. Hasan Sadikin Bandung periode Oktober 2011Januari 2012. Hasil pengukuran didapatkan panjang garis sternoakromion kanan rata-rata $18,35 \pm 1,16 \mathrm{~cm}$.

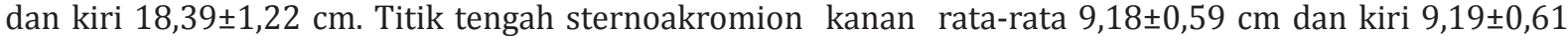

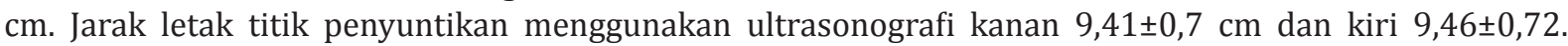
Terdapat korelasi positif ( $r$ kanan $=0,874$ dan $r$ kiri $=0,862$ ) antara garis sternoakromion dan jarak letak titik penyuntikan menggunakan pencitraan ultrasonografi.
\end{abstract}

Kata kunci: Blokade vertikal infraklavikular, letak penyuntikan blokade infraklavikular, pencitraan ultrasonografi

\section{Correlation between the Sternoacromion Line Length and Plexus Brachialis Vertical Infraclavicular Block Injection Site Using Ultrasonography Scan on Adult Males}

\begin{abstract}
Surgery on the lower part of the arm can be managed by brachial plexus vertical infraclavicular block. Needle placement for vertical infraclavicular block is not always at the midpoint of the sternoacromion line. The aim of this study was to find the correlation between sternoacromion length and needle placement using ultrasond scan for vertical infraclavicular block on adults males. This was a cross sectional study measuring the midlle point of sternoacromion line on 48 adult male volunteers whom never had any injury or operation on shoulder areas. Linear probe ultrasound was used to determine the needle placement. This study was conducted in Dr. Hasan Sadikin General Hospital Bandung within the period of October 2011-January 2012. Pearson correlation test and linear regression were used to analyze the data. Result of this study showed an average right strernoacromion length of $18.35 \pm 1.16 \mathrm{~cm}$, an average left sternoacromion leght of $18.39 \pm 1.22 \mathrm{~cm}$, an average midpoint right sternoacromion of $9.18 \pm 0.59 \mathrm{~cm}$, and an average midmpoint left sternoacromion of $9.19 \pm 0.61$. The average ultrasound right point was $9.41 \mathrm{~cm}$ and $9.46 \mathrm{~cm}$ for the left point. Hence, thereare significant correlations ( $\mathrm{r}$ right $=0.874$, $\mathrm{rleft}=0.862$ ) between sternoacromion length and ultrasound injection point for vertical infraclavicular block.
\end{abstract}

Key words: Injection site for infraclavicular block, ultrasound scan, vertical infraclavicular block

Korespondensi: Dedi Fitri Yadi, dr., SpAn. M. Kes, Departemen Anestesiologi dan Terapi Intensif Fakultas Kedokteran Universitas Padjadjaran/Rumah Sakit Dr. Hasan Sadikin Bandung, Tlpn (022) 203-8285, Faks (022) 203-8306, Mobile 081321341101,Email dedifyadi@yahoo.com 


\section{Pendahuluan}

Penatalaksanaan anestesia pada pembedahan ekstremitas superior dapat dilakukan dengan menggunakan anestesia umum atau anestesia regional. ${ }^{1}$ Penatalaksanaan memakai anestesia regional memberikan beberapa keuntungan, di antaranya adalah daerah yang teranestesia terbatas pada bagian tubuh yang dikendalikan saraf tertentu sehingga bagian tubuh yang lain tidak terpengaruh oleh anestesi, berkurangnya kejadian mual dan muntah pascaoperasi, masa pemulihan yang cepat, serta penatalaksanaan nyeri pascaoperasi dengan durasi lebih lama tanpa pemberian analgetik opioid. ${ }^{1,2}$ Blokade saraf perifer merupakan pilihan jenis anestesia yang terbaik untuk operasi pada ekstremitas. ${ }^{3}$

Salah satu metode yang mudah dilakukan yaitu teknik vertical infraclavicular block (VIB) karena sederhana dalam pelaksanaannya dan juga mudah dipelajari. ${ }^{4}$ Vertical infraclavicular block memberikan tingkat keberhasilan yang tinggi, yaitu sebesar 88-95\%., ${ }^{5,6}$ Bila dibanding dengan menggunakan blokade supraklavikular, teknik vertikal infraklavikular mengakibatkan komplikasi yang lebih sedikit serta lebih jarang terjadi. ${ }^{7}$ Bila dibanding dengan pendekatan aksilar, vertikal infraklavikular menghasilkan anestesia yang lebih luas. ${ }^{8-10}$

Blokade di daerah infraklavikular semakin sering dipergunakan karena mudah dilakukan tanpa harus melakukan identifikasi dari saraf muskulokutaneus, medianus, radialis, dan juga ulnaris. Metode ini dapat digunakan dengan risiko minimal untuk terjadi pneumotoraks dan kemungkinan saraf frenikus atau ganglion stelatum teranastesi. ${ }^{11}$

Kilka dkk. telah melaporkan hasil penelitian tentang titikpenyuntikan pleksus brakialisyang berada di titik tengah garis sternoakromion, yaitu garis yang menghubungkan fosa jugularis ke prosesus akromion ventralis. ${ }^{12}$

Penggunaan alatultrasonografi (USG) untuk melakukan identifikasi letak saraf semakin banyak dipergunakan. ${ }^{11}$ Kelebihan pencitraan USG adalah kemampuan melihat saraf serta struktur di sekitar saraf. Ultrasonografi dapat membantu menentukan tempat penyuntikan agar lebih tepat dengan cara mengidentifikasi lokasi pleksus saraf brakialis. ${ }^{13}$

Pada relawan pria dewasa yang diperiksa mempergunakan pencitraan ultrasonografi, tempat penyuntikan VIB tidak selalu tepat di titik Kilka, tetapi ke arah lebih medial atau lateral dari titik Kilka. ${ }^{13}$

Menentukan tempat penyuntikan blokade pleksus brakialis dengan pendekatan vertikal infraklavikular menggunakan Doppler dengan cara mencari pencitraan yang paling jelas dari arteri subklavia di daerah infraklavikular didapatkan bahwa tempat penyuntikan lebih lateral dari titik Kilka dengan rata-rata $6 \mathrm{~mm} .{ }^{5}$

Hasil penelitian di Austria menunjukkan bahwa jarak garis sternoakromion rata-rata pada pria dewasa adalah $21 \mathrm{~cm}$, sedangkan pada hasil penelitian di Belanda dan Amerika Serikat, titik tengah garis sternoakromion rata-rata pada pria dewasa adalah $9,4 \mathrm{~cm}$ sehingga jarak garis sternoakromion rata-rata pada subjek penelitiannya adalah $18,8 \mathrm{~cm} .{ }^{5,13}$

Publikasi penelitian di Indonesia mengenai letak pleksus brakialis dengan pendekatan vertikal infraklafikular belum ditemukan. Belum diketahui apakah diperlukan atau tidak pergeseran dari titik Kilka untuk menentukan tempat penyuntikan anestesi blokade pleksus brakialis pendekatan vertikal infraklavikular di Indonesia.

Penelitian ini bertujuan mendapatkan kolerasi antara panjang garis sternoakromion dan tempat penyuntikan dengan menggunakan pencitraan ultrasonografi (USG) untuk blokade pleksus brakialis vertikal infraklavikular pada pria dewasa.

\section{Subjek dan Metode}

Subjek penelitian adalah relawan pria dewasa dan pasien yang memenuhi kriteria inklusi dan tidak termasuk ke dalam kriteria eksklusi serta bersedia mengikuti penelitian dengan mengisi lembar persetujuan. Kriteria inklusi adalah relawan pria dewasa dan juga pasien yang bersedia mengikuti penelitian. Kriteria eksklusi pada penelitian ini adalah terdapat riwayat trauma pada daerah klavikula serta riwayat operasi pada daerah klavikula.

Penelitian dilakukan di Rumah Sakit Dr. 
Hasan Sadikin Bandung selama bulan Oktober 2011 sampai dengan Januari 2012. Penelitian dilakukan pada 48 pria dewasa yang memenuhi kriteria inklusi.

Penelitian ini merupakan suatu penelitian analitik metode potong lintang (cross sectional) dengan menggunakan analisis korelasi untuk mencari model hubungan antara panjang garis sternoakromion dan tempat penyuntikan menggunakan pencitraan ultrasonografi pada blok pleksus brakialis pendekatan vertikal infraklavikular pada pria dewasa.

Besar sampel ditentukan memakai rumus analisis korelasi dengan taraf kepercayaan $95 \%$, power $80 \%$, dan besar koefisien korelasi $r=0,395$. Hasil pehitungan rumus tersebut diperoleh jumlah sampel sebanyak 48 subjek.

Setelah mendapat persetujuan Komite Etik Penelitian Kesehatan Fakultas Kedokteran Universitas Padjadjaran/RumahSakitDr.Hasan Sadikin Bandung, subjek penelitian dicatat usia, diukur berat badan serta tinggi badan. Relawan diminta membuka pakaian atas, kemudian berbaring pada tempat tidur. Posisi tempat tidur dibuat horizontal tanpa memakai bantal. Tangan relawan pada sisi yang akan diukur diletakkan dengan nyaman di bagian perutnya. Pengukuran garis sternoakromion dilaksanakan dengan cara menandai angulus sternalis dan akromion di satu sisi yang sama dengan spidol, ditarik garis lurus di antara keduanya di bawah tulang klavikula, kemudian diukur panjang garis tersebut dan dicatat.
Tepat di tengah garis sternoakromion ditandai sebagai titik K. Pencitraan mempergunakan ultrasonografi mulai dilaksanakan pada titik $\mathrm{K}$ dengan posisi probe sejajar dengan tubuh relawan, kemudian digeser sampai terlihat arteri subklavia dan fasikulus dari pleksus brakialis di daerah infraklavikular. Pencitraan ultrasonografi memerlukan penggunaan gel untuk menghasilkan gambar ultrasonografi yang lebih baik. Pada waktu terlihat arteri dan fasikulus, letak probe diberi tanda pada garis sternoakromion dari garis tengah longitudinal probe ultrasonografi, kemudian titik ini disebut titik U. Kemudian, diukur jarak titik K ke titik $\mathrm{U}$ pada garis sternoakromion menggunakan penggaris yang kemudian jarak ini disebut D. Hasil jarak D kemudian dikorelasikan dengan jarak garis sternoakromion (Gambar 2).

Pada penelitian ini dilakukan pengukuran panjang garis sternoakromion kanan dan kiri, serta dilakukan penentuan titik tengah kanan dan kiri. Titik tengah ini merupakan letak penyuntikan Kilka, kemudian dilakukan pencitraan ultrasonografi untuk mencari letak titik penyuntikan ultrasound. Dicari perbedaan antara kedua titik tersebut yang dinyatakan dengan D.

Dilakukan uji korelasi untuk mengetahui korelasi panjang garis sternoakromion dengan pergeseran tempat penyuntikan menggunakan pencitraan ultrasonografi. Untuk menentukan uji kolerasi, harus dilakukan terlebih dulu uji normalitas menggunakan Shapiro-Wilk.

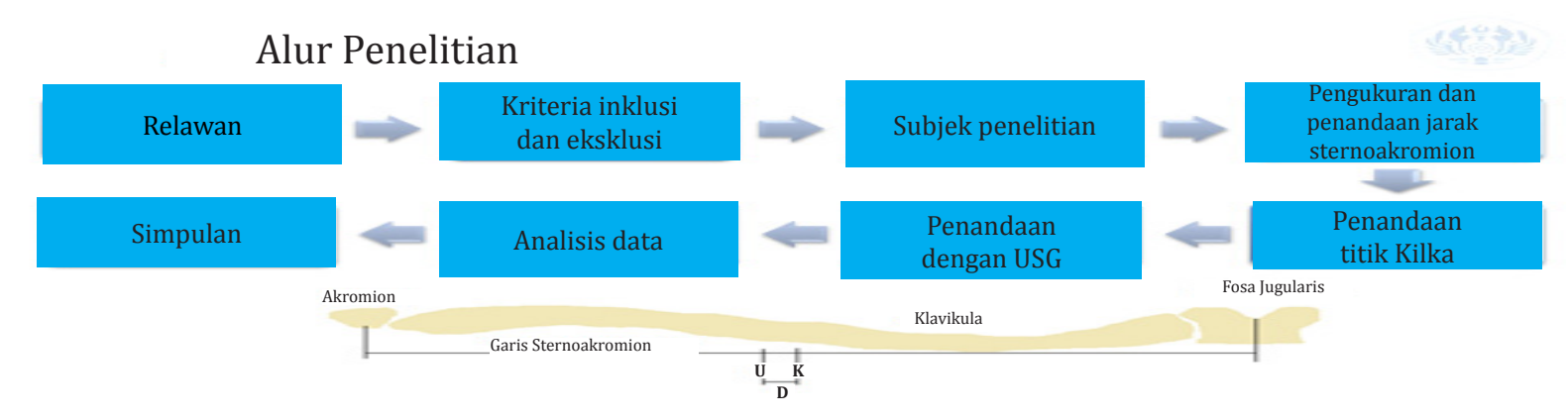

Gambar 1 Letak Titik U dan K pada Tulang Klavikula

Keterangan: $\mathrm{U}=$ letak titik penyuntikan ultrasound

$\mathrm{K}=$ letak titik penyuntikan Kilka

$\mathrm{D}=$ jarak antara titik penyuntikan ultrasound dan Kilka 


\section{Hasil}

Usia subjek penelitian rara-rata adalah 32,27 tahun dengan rentang 25 tahun sampai 42 tahun. Tinggi badan rata-rata didapatkan $167,46 \mathrm{~cm}$ dengan rentang $151 \mathrm{~cm}$ sampai $178 \mathrm{~cm}$, sedangkan berat badan rata-rata pada penelitian ini adalah $72 \mathrm{~kg}$ dengan rentang 47 kg sampai $98 \mathrm{~kg}$ (Tabel 1).

Pengukuran panjang garis sternoakromion pada hasil penelitian ini didapatkan rentang panjang garis sternoakromion kanan dan kiri yang terpendek adalah $15 \mathrm{~cm}$ dan yang terpanjang adalah $21 \mathrm{~cm}$ dengan titik tengah kanan rata-rata sebesar 9,17 $\mathrm{cm}$ dan kiri 9,19 $\mathrm{cm}$. Jarak berdasarkan hasil pencitraan ultrasonografi kanan rata-rata adalah 9,42 cm

Tabel 1 Karakteristik Subjek Penelitian

\begin{tabular}{lc}
\hline \multicolumn{1}{c}{ Karakteristik } & Rata-rata (SD) \\
\hline Usia (tahun) & $32,27(3,76)$ \\
Tinggi badan $(\mathrm{cm})$ & $167,46(4,98)$ \\
Berat badan $(\mathrm{kg})$ & $72(10,95)$ \\
Body mass index $\left(\mathrm{BMI} / \mathrm{kg} / \mathrm{m}^{2}\right)$ & $31,51(9,61)$ \\
\hline
\end{tabular}

dan kiri 9,47 cm (Tabel 2).

Uji normalitas menggunakan Uji ShapiroWilk didapatkan bahwa sebaran data pada penelitian ini terdistribusi normal sehingga
Tabel 2 Hasil Pengukuran Garis Sternoakromion

\begin{tabular}{lc}
\hline \multicolumn{1}{c}{ Pengukuran } & $\begin{array}{c}\text { Rata-rata } \\
\text { (SD) }\end{array}$ \\
\hline Panjang garis sternoakromion & \\
$\quad$ Kanan (cm) & $18,35(1,17)$ \\
$\quad$ Kiri $(\mathrm{cm})$ & $18,39(1,23)$ \\
Titik tengah & \\
$\quad$ Kanan (cm) & $9,17(0,58)$ \\
$\quad$ Kiri $(\mathrm{cm})$ & $9,19(0,61)$ \\
Jarak pencitraan ultrasonografi & \\
$\quad$ Kanan $(\mathrm{cm})$ & $9,42(0,68)$ \\
$\quad$ Kiri $(\mathrm{cm})$ & $9,47(0,71)$ \\
\hline
\end{tabular}

uji kolerasi yang dipergunakan adalah Uji Pearson. Hasil uji kolerasi didapatkan nilai $r$ kanan=0,874 dan r kiri=0,862 (Tabel 3).

Hubungan panjang garis sternoakromion dengan letak penyuntikan yang menggunakan pencitraan ultrasonografi terlihat dari uji kolerasi Pearson yang menunjukkan nilai $r$ kanan $=0,618$ dan $r$ kiri $=1,845$. Nilai $r$ tersebut menunjukkan kekuatan kolerasi positif bahwa semakin besar garis strenoakromion maka jarak letak penyuntikan akan semakin besar (Tabel 4).

\section{Pembahasan}

Pada penelitian ini subjek yang digunakan adalah relawan yang telah dewasa. Hal tersebut

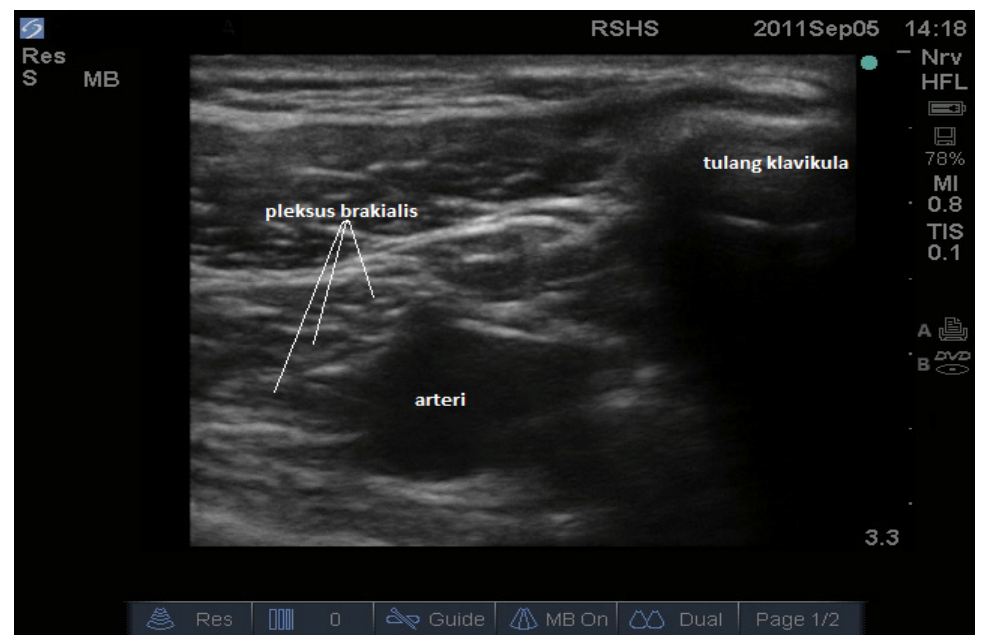

Gambar 2 Hasil Pencitraan Ultrasonografi

Keterangan: Dokumentasi Dedi Fitri Yadi 
Tabel 3 Uji Korelasi

\begin{tabular}{lcc}
\hline & K-kanan & K-kiri \\
\hline K-U kanan & & \\
Pearson correlation & 0,874 & \\
Sig (2 tailed) & 0,000 & \\
N & 48 & \\
K-U kiri & 0,862 \\
Pearson correlation & 0,000 \\
Sig (2 tailed) & 48 \\
N & \\
\hline Keterangan: & $\mathrm{K}=$ titik tengah garis & sternoakromion \\
\multicolumn{2}{l}{ K-U = titik tengah garis sternoakromion +} \\
pergeseran hasil pencitraan ultrasonografi
\end{tabular}

berhubungan dengan pelaksanaan blokade saraf tepi yang hanya dilakukan pada pasien dewasa yang kooperatif selama dilakukan penyuntikan. Penatalaksanaan pasien yang tidak kooperatif dilakukan dalam pembiusan umum. Pengambilan subjek dengan jenis kelamin pria berhubungan dengan masalah etika penelitian karena subjek perlu membuka pakaian bagian atas agar dapat diukur panjang garis sternoakromion dan dilakukan pencitraan ultrasonografi. Subjek penelitian adalah relawan yang tidak pernah mengalami cedera pada daerah tulang klavikula atau operasi tulang klavikula. Hal ini disebabkan kemungkinan telah terjadi perubahan anatomi pada panjang tulang klavikula atau perubahan anatomi pada letak pleksus brakialis di bawah tulang klavikula.

Pelaksanaan blokade pleksus brakialis dengan metode vertical infraclavicular block (VIB) yang selama ini sering digunakan adalah mengambil titik tengah jarak antara fosa jugularis dan akromion. Dari penelitian ini diketahui jarak titik tengah sternoakromion kanan rata-rata adalah $9,17 \pm 0,58 \mathrm{~cm}$ dan kiri adalah 9,19 $\pm 0,61 \mathrm{~cm}$. Dari penelitian Renes dkk. ${ }^{5}$ didapatkan titik tengah garis sternoakromion rata-rata adalah $9,2 \mathrm{~cm}$. Hal tersebut menunjukkan titik tengah garis sternoakromion pada penelitian ini tidak jauh berbeda dengan penelitian Renes dkk. ${ }^{5}$ Letak penyuntikan VIB dari titik tengah sternoakromion dengan hasil ultrasonografi pada bahu kanan rata-rata 2,38 $\mathrm{mm}$ dan pada bahu kiri adalah $2,72 \mathrm{~mm}$. Hal ini menunjukkan bahwa terdapat pergeseran ke arah lateral dari titik tengah garis sternoakromion untuk letak penyuntikan pleksus brakialis metode VIB. Dari penelitian Renes dkk. ${ }^{5}$ menunjukkan perbedaan pergeseran rata-rata dari titik tengah adalah $0,6 \mathrm{~cm}$.

Data penelitian menunjukkan bahwa letak penyuntikan pleksus brakialis adalah lateral dari titik tengah garis sternoakromion. Hasil ini sesuai dengan hasil penelitian-penelitian lain yang menyatakan hal yang sama. ${ }^{4,5,7}$

Pergeseran letak titik Kilka sebagai hasil ultrasonografi didapatkan tidak berkorelasi dengan tinggi badan, berat badan, dan BMI. Korelasi positif didapatkan dengan jarak garis sternoakromion pada bahu kanan dengan Pearson 0,874 dan pada bahu kiri 0,862 . Hal ini sesuai dengan penelitian yang mengungkapkan letak tempat penyuntikan blokade pleksus brakialis dengan teknik VIB yang berhubungan dengan panjang garis sternoakromion. ${ }^{4,5}$

Tabel 4 Analisis Regresi Hubungan antara Garis Sternoakromion dan Letak Penyuntikan Ultrasonografi

\begin{tabular}{lcccc}
\hline \multicolumn{1}{c}{ Variabel } & Koef $\boldsymbol{B}$ & Standar Error & t Hitung & p \\
\hline Kanan & & & & \\
$\quad$ Konstanta & 0,618 & & & \\
$\quad$ Sternoakromion & 1,019 & 0,08 & 12,21 & 0,000 \\
Kiri & & & & \\
$\quad$ Konstanta & 1,845 & & & \\
$\quad$ Sternoakromion & 1,010 & 0,087 & 11,55 & 0,000 \\
\hline
\end{tabular}




\section{Simpulan}

Simpulan pada penelitian ini terdapat korelasi antara panjang garis sternoakromion dan tempat penyuntikan menggunakan pencitraan ultrasonografi untuk blokade pleksus brakialis vertikal infraklavikular pada pria dewasa.

\section{Daftar Pustaka}

1. Yang WT, Chui PT, Metreweli C. Anatomy of the normal brachial plexus revealed by sonography and the role of sonographic guidance in anesthesia of the brachial plexus. AJR. 1998;171:1631-6.

2. Chin K, Singh M, Velayutham V, Chee V. Infraclavicular brachial plexus block for regional anesthesia of the lowe arm (review). The Cochrane Collaboration. 2010:3.

3. Geffen GJV, Gielen M, Venderick D, Scheffer GJ. The use of ultrasound for peripheral nerve blocks. Nederlands Tijdschrift voor Anesthesie. 2005;18:87-94.

4. Neuburger M, Kaiser H, Rembold-Schuster I, Landes H. Vertical infraclavicular block of brachial plexus-a clinical study to the reliability of a new method for plexus anaesthesia of the upper extremity. Anaesthesist. 1998;47:595-9.

5. Renes S, Clark L, Gielen M, Spoormans H, Giele J, Wadhwa A. A simplified approach to vertical infracllavicular brachial plexus blockade using hand-held doppler. Anesth Analg. 2008;106:1012-4.

6. Marhofer P, Greher M, Kapral S. Ultrasound guidance in regional anaesthesia. $\mathrm{Br} \mathrm{J}$
Anaesth. 2005;94:7-17.

7. Macfarlane A, Anderson K. Infraclavicular brachial plexus blocks. Continuing Education in Anesthesia. Crit Care Pain. 2009;9:139-43.

8. Harrald R, Mathieu G. Comparison of the vertical infraclavicular and axillary approaches for brachial plexus aneaesthesia. Acta Anaesthesiol Scand. 2005;49:1501-8.

9. Rettig H, Gielen M, Boersma E, Klein J. A comparison of the vertical infraclavicular and axillary approaches for brachial plexus anaesthesia. Acta Anaesthesiol Scand. 2005;49:1501-8.

10. Heid F, Jage J, Guth M, Bauwe N, Brambrink A. Efficacy of vertical infraclavicular plexus block vs modified axillary plexus block: A prospective, randomized, observerblinded study. Acta Anaesthesiol Scand. 2005;49:677-82.

11. Bigeleisen P, Wilson M. A comparison of two techniques for ultrasound guided infraclavicular block. $\mathrm{Br} \mathrm{J}$ Anaesth. 2006;96(4):502-7.

12. Kilka H, Geiger $P$, Mehrkens $H$. Infraclavicular vertical brachial plexus blockade. A new method for anesthesia of the upper extremity. An anatomical and clinical study. Anaesthesist. 1995;44:33944.

13. Greher M, Retzl G, Niel P, Kamolz L, Marhofer P, Kapral S. Ultrasonographic assessment of topographic anatomy in volunteers suggests a modification of the infraclavicular vertical brachial plexus. $\mathrm{Br}$ J Anaesth. 2002;88(5):632-6. 